\title{
A defence of the requirement to seek consent to withhold and withdraw futile treatments
}

Cameron L Stewart

BEc, LLB(Hons), PhD,

Professor and Director

Centre for Health Governance, Law and Ethics, Sydney Law School University of Sydney, Sydney, NSW.

cameron.stewart@ sydney.edu.au

MJA 2012; 196: 406-408 doi: 10.5694/mjall.10824

\section{Defining futility and why it is impossible}

Part of the problem with the concept of futility is that it is a subjective notion masquerading as a form of professional, objective and scientific assessment. There are many approaches to defining futility, ${ }^{2,3}$ including physiological, ${ }^{4,5}$ qualitative, quantitative and lethal-condition approaches. ${ }^{6}$ None have been universally accepted as an objective test. It was hoped that definitions of futility would allow doctors to resist the compulsion to comply with unreasonable demands. ${ }^{7}$ However, after 30 years of debate, futility still remains inherently and unavoidably subjective.

A better way to deal with determination of futility is to adopt a procedural approach based on clinical consensus and the input of substitute decisionmakers, with avenues for appeal and review. ${ }^{3,8}$ This approach allows health care teams to make a futility assessment and communicate it to the substitute decisionmakers for their consideration and input. If the substitutes and health care team cannot agree about the decision, the substitutes should be able to have it reviewed internally by an independent group, such as a clinical ethics committee. If this review agrees with the assessment and the substitute still disagrees, then an appeal can be made to a legal body (eg, guardianship tribunal or court) for a final determination.

\section{Queensland law does not conflict with common law}

While a requirement to seek consent for futile treatment may appear to conflict with common law (as futile treatments, by definition, cannot be in a patient's best interests), ${ }^{9}$ this simple position belies a more complicated relationship. Futility is not the primary common law test for substitute decision making. The primary test is the best interests test (Box 1). In determining best interests, the common law is not bound to accept futility determinations by doctors, especially when they have been made without consultation and without a fair process for determining the patient's best interests.

In most cases, the judgement of health professionals Ethics and law p 404 regarding futility has been upheld by the courts (Box 2). ${ }^{9}$

\section{Summary}

- Futility assessments, which are unavoidable in end-of-life settings, need to be procedurally fair. This necessitates communication between health professionals and substitute decisionmakers regarding the decision to define treatments as futile.

- The common law test for whether treatment should be withheld or withdrawn is the best interests test. A futile treatment is not in any patient's best interests.

- While it is rare for the law to disagree with a futility determination made by health professionals, if a determination has been made without consultation and fails to reflect the patient's best interests, the courts will overturn it.

- The best regulatory regimes provide for a balance between the powers of health professionals and substitute decisionmakers to make decisions for incompetent patients, and for clear and efficient dispute resolution.

- The Queensland law and its requirement for consent to withhold or withdraw futile treatment represents a good model of futility determination, with clear powers given to substitute decisionmakers and health professionals. Disputes concerning the treatment of incompetent patients automatically trigger the appointment of the adult guardian as the decisionmaker, and there are avenues for appeal.

The main feature of these cases is a good-faith attempt by clinical staff to communicate with the patients' families. These cases show that the common law encourages the seeking of consent (or consensus) from substitute decisionmakers, because it is strong evidence of a robust assessment of the patient's best interests. ${ }^{10}$ It is also clear from these cases that the Guardianship and Administration Act 2000 (Qld) is not as major a departure from the common law as it may first appear. The Queensland law merely formalises the common law requirement for consultation by making it a requirement to seek consent.

It should be noted that other states also require substitute consent to withdrawal of futile treatment. For example, in South Australia, s. 17 (2) of the Consent to Medical Treatment and Palliative Care Act 1995 states that a doctor can withdraw futile treatment, but only "in the absence of an express direction by the patient or the patient's representative to the contrary". There are arguments as to whether this requires futile treatment to be provided, but it is certainly clear that it requires consent to withdraw it. ${ }^{10}$ In Western Australia, the Guardianship and Administration Act 1990 requires that decisions to refuse a life-sustaining measure (a "medical, surgical or nursing procedure directed at supplanting or maintaining a vital bodily function") be made by substitutes. The effect of these provisions is to require consent to withhold or withdraw futile treatments, in the same way as in Queensland. 


\section{The best interests test}

In Re Marion (No 2) (1992) 17 Fam LR 336, the Family Court of Australia created a checklist of factors to consider in assessing the best interests of children. When adapted to include incompetent adults, these factors are:

1. The particular condition of the patient which requires the procedure or treatment

2. The nature of the procedure or treatment proposed

3. The reasons for which it is proposed that the procedure or treatment be carried out

4. The alternative courses of treatment that are available in relation to that condition

5. The desirability of and effect of authorising the procedure or treatment proposed rather than the available alternatives

6. The physical effects on the patient and the psychological and social implications for the patient of:

a) authorising the proposed procedure or treatment

b) not authorising the proposed procedure or treatment

7. The nature and degree of any risk to the patient of:

a) authorising the proposed procedure or treatment

b) not authorising the proposed procedure or treatment

8. The views (if any) expressed by:

a) the guardian(s) of the patient

b) the relatives of the patient

c) a person who is responsible for the daily care and control

of the patient

d) the patient

to the proposed procedure or treatment and to any alternative procedure or treatment.

\section{Clinical staff ignorant of the legal} requirements need to be educated

Lawrence and colleagues claim that the legal obligation to seek consent is poorly understood by Queensland clinical staff. This highlights a broader problem with the legal training of health care professionals - that health law generally appears to be poorly understood. ${ }^{11}$ The answer is not to change the law but to educate health professionals about it. The health professions (and the health service infrastructure that supports them) must also share responsibility for incorporating the law into their practice.

\section{Queensland law does not lead to clinically inappropriate decisions or staff burnout}

Lawrence et al state that seeking consent for futile treatment is inappropriate because it compels a doctor to seek consent to not treat when death is inevitable. ${ }^{1}$ The problem is that the inevitability of death can be overestimated. Misdiagnoses happen regularly. Moreover, an assessment of futility is not always used for patients whose death is inevitable. It is often used for patients whose life is intolerable, which is a very different thing.

Lawrence et al also state that the Queensland law (and its focus on patient autonomy) creates burdens for staff that may lead to emotional burnout. However, the Queensland Guardianship and Administration Act does not have the potential to "exacerbate the conditions for undignified and prolonged deaths". The law is based on the patient's best interests, not the substitute decisionmaker's demands. Seeking consent does not force

\section{Examples of futility disputes from Australian common law}

\section{Northridge $v$ Central Sydney Area Health Service [2000] NSWLR 1241}

Clinicians decided (after 5 days) to withdraw active treatment from a patient who had suffered brain damage after a drug overdose and was said to be in a "chronic vegetative state". A not-for-resuscitation (NFR) order was entered unilaterally on his chart, even though his Glasgow Coma Scale score had risen from 3 to 9, and he was responding to noise. The New South Wales Supreme Court found that the doctors had misdiagnosed the patient's condition using professionally unrecognised criteria and were in breach of the hospital's own policies on NFR orders. The judge ordered that treatment be continued and that future decisions about the patient's treatment go back to the court.

\section{Messiha $v$ South East Health [2004] NSWSC 1061}

The NSW Supreme Court upheld a decision to withdraw life-sustaining treatment from a 75-year-old man with severe hypoxic brain damage. Soon after admission, the patient had a complete absence of cortical activity, and efforts were made to communicate the poor prognosis to the family. The family disagreed with the diagnosis and continued to do so, even after an independent neurologist reviewed the case and agreed with the decision to withdraw active treatment. The court upheld the clinical assessment of the patient's best interests, finding that it would be rare for judges to disagree with a clinical assessment of futility.

\section{Australian Capital Territory v JT [2009] ACTSC 105}

JT was a 69-year-old man with chronic psychosis who habitually fasted. His weight had fallen to dangerous levels and he was refusing nasogastric feeding. The authorities responsible for his care sought permission to withhold artificial feeding by percutaneous endoscopic gastrostomy (PEG) tube, as they believed that force-feeding him with a PEG tube was futile. No independent assessment had been sought. The court found that JT was incompetent and that the Territory had a duty to provide treatment that was not futile. Force-feeding was not futile in this case as it could still preserve life. The fact that JT's underlying psychosis would likely reassert itself did not make the treatment futile; nor was it futile because he was resistant to feeding, and force-feeding was distressing to both him and the staff.

\section{Slaveski v Austin Health [2010] VSC 493}

The Supreme Court of Victoria upheld the clinical decision to withdraw life-sustaining treatment from a 71-year-old man who had a catastrophic brainstem haemorrhage. The prospect of a meaningful neurological recovery was considered to be negligible and all the health care team agreed that, should he survive, he would remain in a "locked in" state. The relationship between family members and the treatment team had broken down. Independent experts organised by the court to assess the patient agreed with the initial decision that treatment was futile. The judge stated that the court's power was to protect the right of incompetent patients to receive treatment, but not "extraordinary, excessively burdensome, intrusive or futile medical treatment, sustenance and support".

doctors to treat. If substitutes fail to act in the patient's best interests and demand futile treatment, their decisions should be overturned by the Adult Guardian (the government's official guardian), the Queensland Civil and Administrative Tribunal (QCAT) or the Supreme Court. If the treatment is truly futile, it will be withdrawn. If staff decide that it is easier to not challenge a bad decision and just provide treatment, that would be a failure of professional responsibility, not a flaw in the legislation.

\section{Substitute decisionmakers may find the decision difficult but should still be consulted}

Lawrence et al raise questions about the ability of family members to cope with substitute decision making. ${ }^{1}$ The underlying concern is that health professionals will be bound by poor decisions made by families under pressure. Poor decisions will undoubtedly be made, but no one will be 
bound by them, as the legislation provides a clear review mechanism for such decisions. Nor is the fact that some substitute decisionmakers might fail in their task a good reason for denying all substitute decisionmakers the right to be involved. Most families will be more than competent and will help to improve the quality of decisions.

\section{Good laws are a necessary condition for good health care}

The Queensland legislation is currently one of the better regulatory regimes for end-of-life decisions in Australia. It gives power to everyone involved in these decisions to have their say. By doing so, it provides the basic framework for a balanced assessment of the patient's best interests. It provides clear avenues for dispute resolution, including automatic appointment of the Adult Guardian in cases of dispute. This law is not a major departure from the common law or legislation in other states, and it is not clear that the requirement to seek consent to remove futile treatment will have deleterious consequences - there is certainly no evidence of this in the 12 years of the law's operation. Improvements can undoubtedly be made policies can be written that clearly set out the rules for health professionals and families in making these decisions. Processes can be forged that will ensure the quick involvement of the Adult Guardian and QCAT. The law provides a framework that can be brought to life by effective procedures and policies.

Finally, it is worth remembering that good laws will not solve all problems, but bad laws guarantee they will arise. Good laws are a necessary, but not a sufficient, condition for good health care. ${ }^{12}$

Competing interests: No relevant disclosures.

Provenance: Commissioned; externally peer reviewed.

1 Lawrence S, Willmott L, Milligan E, et al. Autonomy versus futility? Barriers to good clinical practice in end-of-life care: a Queensland case. Med J Aust 2012; 196: 404-405.

2 Kerridge I, Mitchell K, McPhee J. Defining medical futility in ethics, law and clinical practice: an exercise in futility? J Law Med 1997; 4: 235-242.

3 Stewart C. Futility determination as a process: problems with medical sovereignty, legal issues and the strengths and weakness of the procedural approach. J Bioeth Inq 2011; 8: 155-163.

4 Dzielak RJ. Physicians lose the tug of war to pull the plug: the debate about continued futile medical care. J Marshall L Rev 1995; 28: 733.

5 Callahan D. Medical futility, medical necessity. The-problem-without-a-name. Hastings Cent Rep 1991; 21: 30-35.

6 Schneiderman LJ, Jecker NS, Jonsen AR. Medical futility: its meaning and ethical implications. Ann Intern Med 1990; 112: 949-954.

7 Wilkinson DJ, Savulescu J. Knowing when to stop: futility in the ICU. Curr Opin Anaesthesiol 2011; 24: 160-165. doi: 10.1097/AC0.0b013e328343c5af.

8 Truog RD. Counterpoint: The Texas advance directives act is ethically flawed: medical futility disputes must be resolved by a fair process. Chest 2009; 136 : 968-971.

9 Skene L. The Schiavo and Korp cases: conceptualising end-of-life decisionmaking. J Law Med 2005; 13: 223-229.

10 Skene L. Withholding and withdrawing treatment in South Australia when patients, parents or guardians insist that treatment must be continued. Adelaide Law Rev 2003; 24: 161-185. http://www.austlii.edu.au/au/journals/ AdelLawRw/2003/17.pdf (accessed Feb 2012).

11 Skene L, Smallwood R. Informed consent: lessons from Australia. BMJ 2002; 324: 39-41.

12 Stewart CL. Law and cancer at the end of life: the problem of nomoigenic harms and the five desiderata of death law. Public Health 2011; 125: 905-918. doi: 10.1016/j.puhe.2011.10.001. 